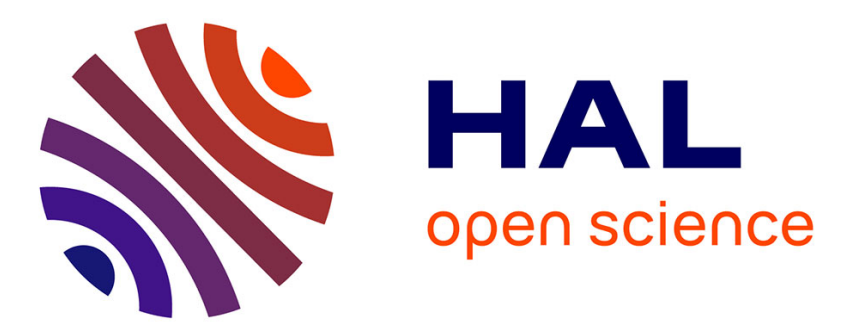

\title{
An Optimization method for the Configuration of Inter Array Cables for Floating Offshore Wind Farm.
}

Yann Poirette, Martin Guiton, Guillaume Huwart, Delphine Sinoquet, Jean Leroy

\section{- To cite this version:}

Yann Poirette, Martin Guiton, Guillaume Huwart, Delphine Sinoquet, Jean Leroy. An Optimization method for the Configuration of Inter Array Cables for Floating Offshore Wind Farm.. OMAE 2017 - International Conference on Ocean, Offshore and Artic Engineering, Jun 2017, Trondheim, Norway. hal-02284402

\section{HAL Id: hal-02284402 \\ https: / hal-ifp.archives-ouvertes.fr/hal-02284402}

Submitted on 11 Sep 2019

HAL is a multi-disciplinary open access archive for the deposit and dissemination of scientific research documents, whether they are published or not. The documents may come from teaching and research institutions in France or abroad, or from public or private research centers.
L'archive ouverte pluridisciplinaire HAL, est destinée au dépôt et à la diffusion de documents scientifiques de niveau recherche, publiés ou non, émanant des établissements d'enseignement et de recherche français ou étrangers, des laboratoires publics ou privés. 


\section{DRAFT OMAE2017-61655}

\section{AN OPTIMIZATION METHOD FOR THE CONFIGURATION OF INTER ARRAY CABLES FOR FLOATING OFFSHORE WIND FARM}

\author{
Yann Poirette \\ IFP Energies nouvelles \\ Rond-point de l'échangeur de Solaize, BP 3, \\ 69360 Solaize, France
}

\author{
Martin Guiton \\ IFP Energies nouvelles \\ Rond-point de l'échangeur de Solaize, BP 3, \\ 69360 Solaize, France
}

\author{
Guillaume Huwart \\ IFP Energies nouvelles \\ Rond-point de l'échangeur de \\ Solaize, BP 3, \\ 69360 Solaize, France
}

\author{
Delphine Sinoquet \\ IFP Energies nouvelles \\ 1 et 4 avenue de Bois Préau, \\ 92852 Rueil-Malmaison Cedex,, \\ France
}

\author{
Jean Marc Leroy \\ IFP Energies nouvelles \\ Rond-point de l'échangeur de \\ Solaize, BP 3, \\ 69360 Solaize, France
}

\begin{abstract}
IFP Energies nouvelles (IFPEN) is involved for many years in various projects for the development of floating offshore wind turbines. The commercial deployment of such technologies is planned for 2020 .
\end{abstract}

The present paper proposes a methodology for the numerical optimization of the inter array cable configuration. To illustrate the potential of such an optimization, results are presented for a case study with a specific floating foundation concept [1].

The optimization study performed aims to define the least expensive configuration satisfying mechanical constraints under extreme environmental conditions. The parameters to be optimized are the total length, the armoring, the stiffener geometry and the buoyancy modules. The insulated electrical conductors and overall sheath are not concerned by this optimization. The simulations are carried out using DeepLines $^{\text {TM }}$, a Finite Element software dedicated to simulate offshore floating structures in their marine environment. The optimization problem is solved using an IFPEN in-house tool, which integrates a state of the art derivative-free trust region optimization method extended to nonlinear constrained problems. The latter functionality is essential for this type of optimization problem where nonlinear constraints are introduced such as maximum tension, no compression, maximum curvature and elongation, and the aerohydrodynamic simulation solver does not provide any gradient information.

The optimization tool is able to find various local feasible extrema thanks to a multi-start approach, which leads to several solutions of the cable configuration. The sensitivity to the choice of the initial point is demonstrated, illustrating the complexity of the feasible domain and the resulting difficulty in finding the global optimum configuration.

\section{INTRODUCTION}

The first commercial offshore wind farms appeared in the early nineties giving then new opportunity for the development of renewable energy sources. Today, fixed offshore wind turbines largely contribute to renewable energy produced from ocean (in 2015, $12 \mathrm{GW}$ of offshore wind capacity [2] vs $0.53 \mathrm{GW}$ for other renewable marine energy sources [3]). Nevertheless, the deployment of fixed bottom structures for offshore wind is limited in water depth mainly due to economic reasons. The floating offshore wind turbines are currently developed to extend this water depth limitation. The first floating offshore wind turbines have been connected to grid in 2009 (Hywind, in Norway) and 2011 (WindFloat, in Portugal), see [4]. The first tender for floating offshore wind pilots has 
been launched in 2015 in France [5]. Nevertheless, the costs of such projects remain still high and need to be optimized, to accelerate the deployment of floating wind turbines. In the cost breakdown of an offshore wind farm, the inter array cable cost accounts for about 10 to $15 \%$ and represents a significant amount of the capital cost [6]. This motivates the optimization of the configuration of inter array cables.

Automated optimization remains still new in the design process of offshore structures. Nevertheless, the global energy economic context and the emergence of new technologies for renewable marine energy sources lead the engineers to develop and use optimization tools, see for example the pioneering work of [7] on the hydrodynamic shape optimization of large offshore floating structures for oil and gas production, and more recently [8] and [9] on the optimization of oil and gas risers and umbilicals.

In their review about design optimization of wind turbine structures, Muskulus et al [10] classify first the papers according to the kind of analysis: static analysis, frequency domain analysis or time domain analysis, analysis which integrate increasing complexity in the model. Most of the studies they referenced aim to save structure weight. They also mentioned the specificity of floating wind turbine optimization with a more non-linear dynamic problem. At last, they deliver some recommendations for optimization studies. In particular, they underline the crucial importance to correctly estimate the gradient when using a gradient based optimization method, recommending to use as much as possible analytical approaches (e.g. [11] for an aeroelastic optimization of flexible aircraft with an adjoint approach). However, Muskulus et al. also explain in the same review paper that users of the dedicated aero-hydrodynamic software generally do not have access to the source code or to a proper documentation required for analytical gradient estimation.

In their recent works, Chew et al. [12] propose an optimization methodology of fixed foundation for offshore wind turbine with analytical gradients. The simulations are performed in the time domain using a linear hydro-elastic solver with aero-servo loads calculated by a specific model. The constraints include sizing, eigenfrequency, extreme and fatigue loads. They highlight strong limitations in the Finite Difference gradient approximation when compared to analytical gradients. Especially, the choice of the perturbation step size of Finite Differences is critical. They also indicate that the decoupled aerodynamic and hydrodynamic approach could be insufficiently accurate for more flexible non-linear structures.

Brommundt et al. [13] use the simulation consuming Nelder-Mead simplex algorithm for a mooring system optimization of floating wind turbines, with constraints approximately represented by penalty functions. Simulations are performed in frequency domain. The authors underline the limitations of such calculations for the case study of semisubmersible floater that they investigate.

In [14], the authors propose to use an integrated optimization tool to minimize the cost of the floating support, mooring system and power cable for offshore wind turbine. The computations are performed in the frequency domain. The specific optimization tool is extended from a project for optimization of mooring and riser in deep water and uses a Sequential Quadratic Programming implementation (NLPQL,[15]), based on a gradient search method. A limitation of this optimization application is, as already pointed out, the use of Finite Difference approximation of derivatives.

Other studies are dedicated to optimization of the inter array layout design of the wind farm in order to maximize the energy yield and minimize the wake losses. The earliest studies on wind farm optimization used genetic algorithms [16] or evolutionary strategy algorithms [17] which are expensive in terms of simulations.

In the present paper, we propose to implement a methodology to optimize the configuration of the inter array cable of a floating offshore wind farm based on the derivativefree Sequential Quadratic Approximation (SQA) algorithm developed by IFPEN, which allows to integrate non-linear constraints ([18], [19], [20]). This algorithm relies on a local quadratic interpolation within a trust region which is updated during the optimization ([21], [22]). It provides an efficient way to avoid the time and error limitations of Finite Difference gradient computations, or for the general case, when the aerohydrodynamic simulation does not provide any gradient information. The constraints are in that case labeled as "blackbox".

Furthermore, we propose a methodology for choosing the relevant set of parameters to be optimized via a sensitivity analysis and for the choice of the initial points of a multi-start optimization approach. Finally, Finite Element Method (FEM) computations in time domain performed in this paper allow to achieve a high accuracy even for highly non-linear extreme loading cases. The potential of this methodology is illustrated with a case study of a lazy-wave power cable configuration. We consider 28 Ultimate Limit State loading cases from a Mediterranean environment, and an IFPEN floater design for a 3.6 MW wind turbine.

\section{CASE STUDY}

The power cable considered in this study is a classical three-core inter array cable of offshore wind farm in a lazy wave configuration, shown in Figure 1. To define the extreme load cases on the power cable, a floater derived from the concept described in [1] has been used. 
The floater has been designed here to support a $3.6 \mathrm{MW}$ wind turbine for a typical Mediterranean environmental conditions. The main features of the wind turbine have been defined based on an industrial $3.6 \mathrm{MW}$ wind turbine. The rotor nacelle assembly and tower mass are about 210 tons and 215 tons respectively. The hub height according to mean sea level is 71.8 $\mathrm{m}$ and the rotor diameter is $107 \mathrm{~m}$.

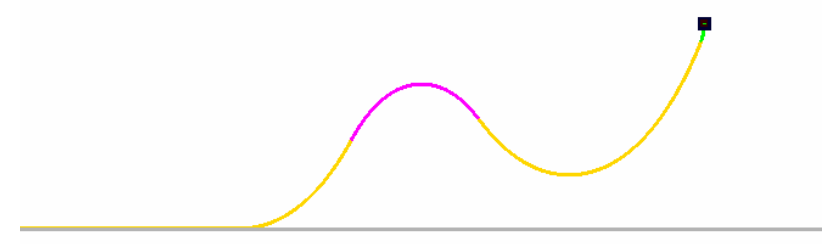

Figure 1: initial cable geometry. The pink part of the curve represents the cable with buoyancy modules.

The environmental conditions considered in this study correspond to typical mean values of various metocean data from the Mediterranean sea. Two extreme design load cases were then considered, depending on whether the wind turbine is in production or not (Table 1). Note that the parked cases associating 50 years marginal return period for wave, current and wind, are particularly severe.

Table 1: Design Load Cases (ULS).

\begin{tabular}{|c|c|c|c|c|}
\cline { 2 - 5 } \multicolumn{1}{c|}{} & \multicolumn{2}{c|}{ Wave } & Current & Wind \\
Speed & Speed \\
\hline \multirow{4}{*}{$\begin{array}{c}\text { Production } \\
\text { case }\end{array}$} & $\mathrm{H}_{\text {s-1 year }}$ & $\begin{array}{c}\text { Associated } \mathrm{T}_{\mathrm{p}} \\
-2 \mathrm{~s}\end{array}$ & no & $\mathrm{V}_{\text {cut-out }}$ \\
\cline { 2 - 5 } & $\mathrm{H}_{\mathrm{s}-1 \text { year }}$ & Associated $\mathrm{T}_{\mathrm{p}}$ & no & $\mathrm{V}_{\text {cut-out }}$ \\
\cline { 2 - 5 } & $\mathrm{H}_{\mathrm{s}-1 \text { year }}$ & $\begin{array}{c}\text { Associated } \mathrm{T}_{\mathrm{p}} \\
+2 \mathrm{~s}\end{array}$ & no & $\mathrm{V}_{\text {cut-out }}$ \\
\hline \multirow{3}{*}{ Parked case } & $\mathrm{H}_{\mathrm{s}-50 \text { year }}$ & $\begin{array}{c}\text { Associated } \mathrm{T}_{\mathrm{p}} \\
-2 \mathrm{~s}\end{array}$ & Cur. 50years & $\mathrm{V}_{\text {50year }}$ \\
\cline { 2 - 5 } & $\mathrm{H}_{\mathrm{s}-50 \text { year }}$ & Associated $\mathrm{T}_{\mathrm{p}}$ & Cur. 50years & $\mathrm{V}_{\text {50year }}$ \\
\hline
\end{tabular}

From these data, 28 load cases have been defined based on wave, current or wind heading combinations.

The dynamic behavior of the floater is calculated using Deeplines $^{\mathrm{TM}}$ [23]. This software is dedicated to offshore structure analysis with FEM and it is co-developed by IFPEN and Principia. It computes hydrodynamic and aerodynamic loads applied on fixed or moored offshore structures, and internal stress in the structure or mooring lines. The FEM simulation first computes a static state, and then a dynamic evolution around it.

The wind turbine is modeled as a mass point where mean aerodynamic loads depending on wind speed are applied. The tower is modeled using beam elements. The floater is modeled as a rigid body with hydrodynamic database calculated using Diodore $^{\mathrm{TM}}$ [24].

The electrical cable is modeled using beam elements with finite rotations and small strain kinematics.

The environment is modeled as follow:

- the waves are defined as JONSWAP spectrum using Hs, Tp shown in Table 1;

- the current, if any, is defined by a constant piecewise linear speed along the depth,

- the modeling of the wind effect depends on the load case considered: in production case, the wind is not modeled but the thrust and torque are calculated depending on constant wind speed considered in Table 1 and applied at the hub level. In parked conditions the wind is defined by a constant vertical profile.

Note that the current and wind loads are taken into account for the static state calculation, while the wave loads are computed during the dynamic simulation.

Considering the low mass of the power cable compared to the floating support, no interaction is considered between the floater behavior and the cable behavior. Then, the movements of the floater have been calculated beforehand for each of the 28 loading cases in time domain calculation. The time series of displacement for the six degrees of freedom are applied on the top of every studied power cable.

The set of parameters related to the power cable for the configuration optimization process are the following:

- $L_{l c}$ : length of the head part of the cable before the buoyancy modules,

- $L_{b}$ : length of the buoyancy part of the cable,

- $L_{c}$ : total cable length,

- $D_{c}$ : cable diameter,

- $D_{b}$ : buoyancy modules diameter,

- $L_{s}$ : length of the stiffener

- $D_{s b}$ : diameter of the base of the stiffener.

\section{LARGE SCALE MECHANICAL PROPERTIES OF THE POWER CABLE}

A classical cross section of the inter-array power cable is shown in Figure 2. The geometry of the internal core which contains in particular three insulated conductors will be assumed to be fixed in this study, just as the external sheath diameter. The cable structure design focuses here on the wire armor dimensions. The function of the steel armors is to withstand the mechanical tension and to limit the curvature due to the submarine movements imposed by waves and currents. 


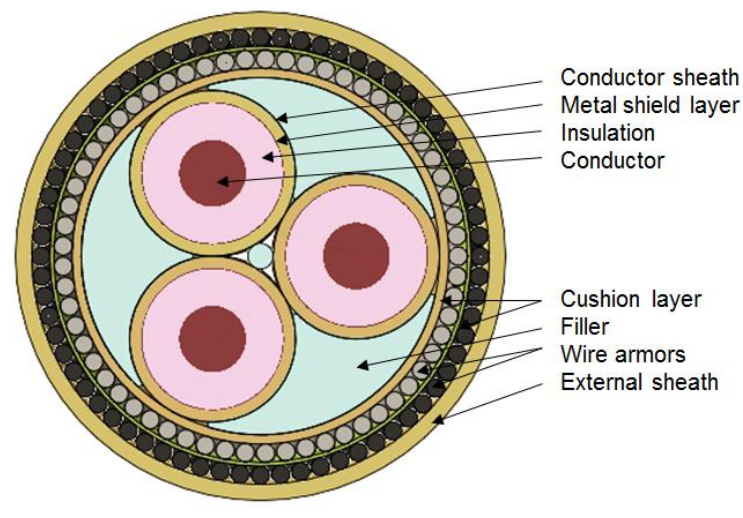

Figure 2: typical cross section of MVAC cable.

Figure 3 illustrates the cable geometry.

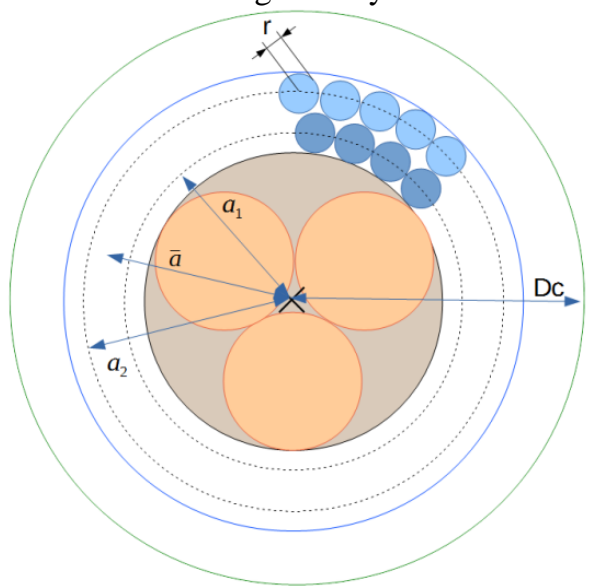

Figure 3 : cable geometry for the optimization.

The cable is composed of two armor layers with a mean radius $\bar{a}=\frac{a_{1}+a_{2}}{2}$. Each wire is made of steel with elasticity modulus $\mathrm{E}=210 \mathrm{GPa}$ and shear modulus $\mathrm{G}=80 \mathrm{GPa}$.

The average number of wires for the two armoring layers is denoted $\bar{n}$; the radius of an armor is $r$, the lay angle of each armor (i.e. angle between the axis and the armoring wire) is $\alpha$ fixed here to $10^{\circ}$ and the cable diameter is denoted $D_{c}$. For each value of $D_{c}$ during the optimization process, $r$ and $\bar{a}$ are then updated according to linear relationships in $D_{c}$.

After classical mechanical considerations, the axial stiffness $E A$ and the flexural stiffness $E I$ of the cable is written as:

$$
\begin{gathered}
(E A)=\bar{n} \cdot \cos ^{3}(\alpha) \cdot \pi r^{2} \cdot E+ \\
(E A)_{\text {core }}+(E A)_{\text {sheath }} \\
(E I)=\bar{n} \cdot \frac{2 \cdot \cos (\alpha)}{\frac{1+\cos ^{2}(\alpha)}{E I_{b}}+\frac{\sin ^{2}(\alpha)}{G I_{p}}}+ \\
(E I)_{\text {core }}+(E I)_{\text {sheath }}
\end{gathered}
$$

$$
I_{b}=\frac{\pi d^{4}}{64} \quad ; \quad I_{p}=\frac{\pi d^{4}}{32}
$$

Based on values found in the literature, axial stiffness and flexural stiffness are fixed as:

$$
\begin{aligned}
& (E A)_{\text {core }}+(E A)_{\text {sheath }}=90 \cdot 10^{6} \mathrm{~N} \\
& (E I)_{\text {core }}+(E I)_{\text {sheath }}=6.8 \mathrm{kN} . \mathrm{m}^{2} .
\end{aligned}
$$

These properties are used for the large scale hydrodynamic momentum balance solved by Deeplines ${ }^{\mathrm{TM}}$ which also requires to define the linear mass of the cable :

$$
\begin{aligned}
& \quad m l_{\text {cable }}=\frac{\bar{n} \cdot \pi r^{2}}{\cos (\alpha)} \cdot \rho+m l_{\text {core }}+m l_{\text {sheath }} \quad \text { Eq. } 3 \\
& \rho=7850 \mathrm{~kg} \cdot \mathrm{m}^{-3} ; m l_{\text {core }}+m l_{\text {sheath }}=15 \mathrm{~kg} \cdot \mathrm{m}^{-1} .
\end{aligned}
$$

with

\section{SMALL SCALE STRESSES ON THE ARMOR WIRES}

In the following, a simplified analysis, based on the helix geometry of armors and assuming a constant radius is used to assess the stresses in the armors. A more realistic approach could be used, such as the numerical model described in [25].

Considering that armor layers withstand the axial force, the mean axial stress within an armor wire is defined as:

$$
\bar{\sigma}=\frac{F_{\text {total }}}{\bar{n} \cos (\alpha) A}
$$

Eq. 4

where $F_{\text {total }}$ is the resulting axial force for all the wires and $A$ the wire cross section area.

The Figure 4 represents an elementary part of an armor wire with the tangent and normal unit vector denoted $\vec{t}$ and $\vec{n}$, respectively. The tangential forces applied at the left and right boundaries are equilibrated by a linear friction force $f F_{n}$, with $f=0.15$ the friction coefficient and $F_{n}$ the linear contact force.

Reminding the normal curvature of an helix to be:

$$
\frac{\overrightarrow{d t}}{d s} \cdot \vec{n}=C_{N}=\frac{\sin ^{2} \alpha}{a}
$$

Eq. 5

one obtains from the equilibrium projected on $\vec{n}$ :

$$
A \sigma \frac{\sin ^{2} \alpha}{a}=F_{n} \text {. }
$$

with 


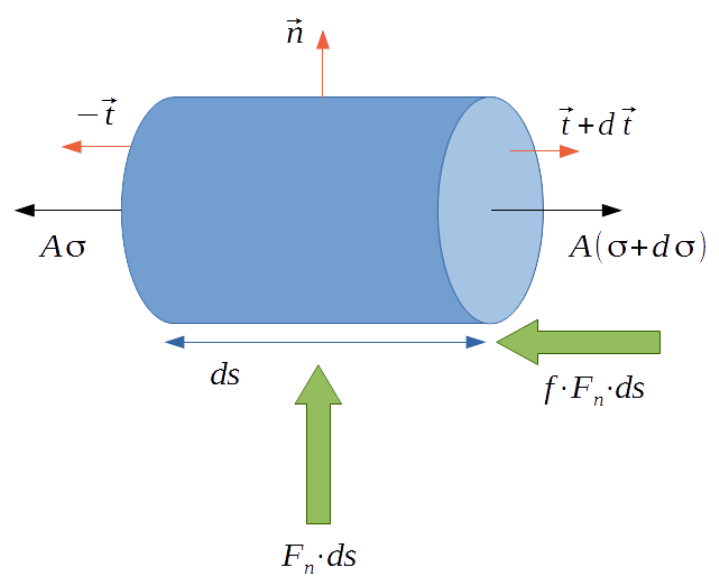

Figure 4: mechanical equilibrium on an elementary wire part.

The equilibrium projected on $\vec{t}$ provides the Coulomb criterion:

$$
A|d \sigma| \leq f F_{n} d s .
$$

Let us define a circumferential angle $\theta$ along the armor helix during the bending set to $0^{\circ}$ at the outer-arc and $180^{\circ}$ at the inner arc. When the sliding is not triggered, axial stress reads:

$$
\sigma_{\text {stick }}=E \frac{a}{R} \cos ^{2} \alpha \cos \theta
$$

Eq. 8

Differentiating Eq.8, Eq.7 becomes:

$$
E \frac{1}{R} \cos ^{2} \alpha \sin \theta \sin \alpha \leq f \sigma \frac{\sin ^{2} \alpha}{a} .
$$

The sliding is triggered first at the neutral fibers $\left(\theta=\frac{\pi}{2}\right)$. Integrating the Coulomb criterion, one obtains the increment of axial stress due to bending:

$$
\Delta \sigma(\theta)=\frac{f}{A} \frac{F_{t o t a l}}{\bar{n} \cos (\alpha)} \sin (\alpha) \cdot\left(\frac{\pi}{2}-\theta\right)
$$

Eq. 10

so that the total axial stress is finally computed as:

$\sigma(\theta)=\bar{\sigma}\left[1+f \sin (\alpha) \cdot\left(\frac{\pi}{2}-\theta\right)\right] \quad$ for $\theta \in[0 ; \pi] . \quad$ Eq. 11

\section{POWER CABLE CONFIGURATION, OPTIMIZATION PROBLEM}

The admissible domains of the seven configuration design parameters introduced in the previous section are defined as:

- $\quad L_{l \mathrm{c}}$ in $[60 \mathrm{~m}, 90 \mathrm{~m}]$

- $L_{b}$ in [30m, 60m]

- $\quad L_{c}$ in $[520 \mathrm{~m}, 550 \mathrm{~m}]$

- $D_{c}$ in $[120 \mathrm{~mm}, 135 \mathrm{~mm}]$

- $D_{b}$ in $\left[2 D_{c}, 4 D_{c}\right]$
- $L_{s}$ in $[3 \mathrm{~m}, 6 \mathrm{~m}]$

- $D_{s b}$ in $\left[2.5 D_{c}, 3.5 D_{c}\right]$.

The optimization problem aims to find a set of parameter values in their feasible domain which minimizes an objective material cost function defined as:

$$
\begin{gathered}
C\left(L_{c}, L_{b}, D_{c}, D_{b}, L_{s}, D_{s b}\right)=\bar{n} \cdot \cos (\alpha) \cdot \pi \cdot \mathrm{r}^{2} L_{c} \cdot C_{v c} \\
+L_{b} \cdot \pi \cdot\left(\frac{D_{b}{ }^{2}}{4}-\frac{D_{c}{ }^{2}}{4}\right) \cdot C_{v b} \\
+\left(\frac{\pi}{12} \cdot\left(\frac{D_{s b}^{3}-D_{s e}^{2} D_{s b}+D_{s e}^{3}}{D_{s e}}\right)-\pi \cdot \frac{D_{c}{ }^{2}}{4}\right) \cdot L_{s} \cdot C_{v s}
\end{gathered}
$$

Eq. 12

with $C_{v c}, C_{v b}$ and $C_{v s}$ the volumetric costs of the cable, of the buoyancy modules and of the stiffener respectively and $D_{s e}=D_{c}+10 \mathrm{~mm}$, the diameter at the end of the stiffener. The first, second and third terms represent the cost of the armors, the buoyancy modules and the stiffener respectively.

The particularity of our optimization problem lies in the introduction of constraints to make the design solution acceptable. Indeed, the optimization solution has to respect the following six black-box constraints which are nonlinear with respect to the optimization parameters:

- $\mathrm{C} 1: \max _{D L C, s, t} \sigma>0$

- $\mathrm{C} 2: \min _{D L C, s, t} \sigma<\frac{2}{3} R e=660 M P \mathrm{a}$

- C3: $\max _{D L C, s, t}|\gamma|<0.25 m^{-1}$ Eq. 13

- $\quad$ C4: $\max _{D L C, s, t} \varepsilon<0.1 \%$

- C5: $\min _{D L C, s, t} Z_{\text {firstpart }}-0.5 D c>-W_{d}$

- $\mathrm{C} 6: \max _{D L C, s, t} z_{\text {buoys }}+0.5 D c<0$

with $\gamma$ the cable curvature, $\varepsilon$ the cable elongation, $z_{\text {firstpart }}$ the $z$ coordinate of a cable point before the buoyant segment and $z_{\text {buoys }}$ the $z$ coordinate of a point in the buoyant segment. The $z$ coordinate decreases from 0 at the sea level to $-W_{d}$ at the sea floor.

The max and min operators refer to the 28 loading cases (Table 1 ), the curvilinear abscissa along the cable $s$, and the time $t$.

$\mathrm{C} 1$ prevents from any compression in order to avoid a disorganization of the cable components. $\mathrm{C} 2$ corresponds to the armor limit state in tension, as $66 \%$ of the yield strength $R e=1000 \mathrm{MPa}$ as for the normal safety class in [26]. To be conservative, we choose the worst case which is at the outerarc. The curvature limit of C3 comes from manufacturer's data. C4 elongation threshold is the same as [27]. Finally, C5 and C6 aim to prevent the cable from touching the sea floor, and the buoyancy modules from emerging from the water, respectively. In the following, these nonlinear constraints are normalized (to be close to $[-100,100])$ and reformulated so that the feasible domain is $\mathbb{R}^{-*}$. 
Finally, this problem is solved with a workflow chaining different software: the optimization loop is controlled with an IFPEN in house general optimization library and communicates through Python scripts to Deeplines ${ }^{\mathrm{TM}}$ FEM solver which is run through multi-threading parallelization.

In this study, the SQA algorithm developed by IFPEN ([18],[19],[20]) is used. This is a local derivative free optimization method based on quadratic interpolation models controlled in a trust region, generalizing the NEWUOA algorithm [22] to the case of non-linear black-box constrained problems.

\section{RESULTS}

Firstly, a global sensitivity analysis has been conducted to check the influence of the selected design parameters on the simulation outputs thanks to a Latin Hypercube Sampling (LHS) of 600 simulated points. To reduce computational time, only 6 loading cases over the 28 are selected to be particularly severe, all from parked DLC.

The presented results are the Sobol's indices based on the Sobol decomposition of the variance of the outputs with respect to the inputs [28]. The total and the first order indices for each design parameters are displayed in percentiles of the total variance on Figure 5, Figure 6 and Figure 7 for the most active constraints : C1, C3 and C5. The first order index for a given parameter measures the part of the response variance explained by the effect of this parameter and effect of functions of only this parameter, whereas the total index measures the part of the response variance explained by all the effects in which this parameter plays a role (including interactions with other parameters). Note that a parameter is not displayed if its influence is smaller than $2 \%$ of the total variance.

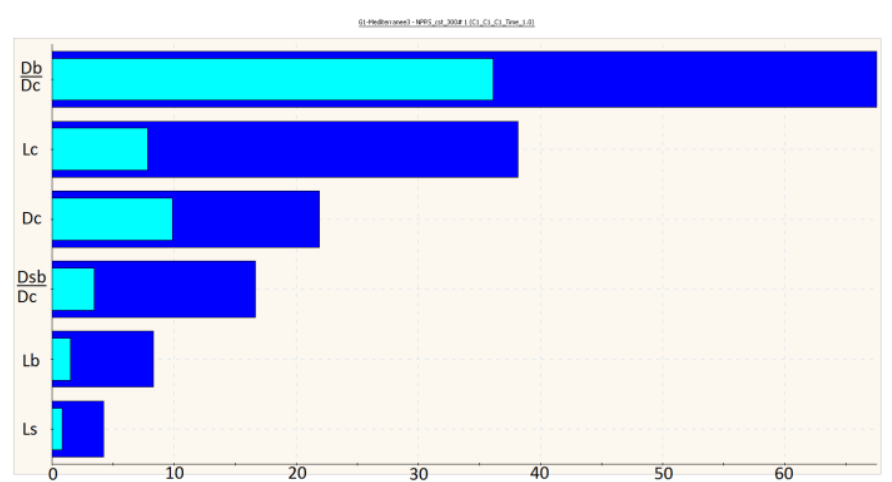

Figure 5 : First order (light blue) and total (blue) effects of the design parameters in percent, for $\mathrm{C} 1$ constraint variance.

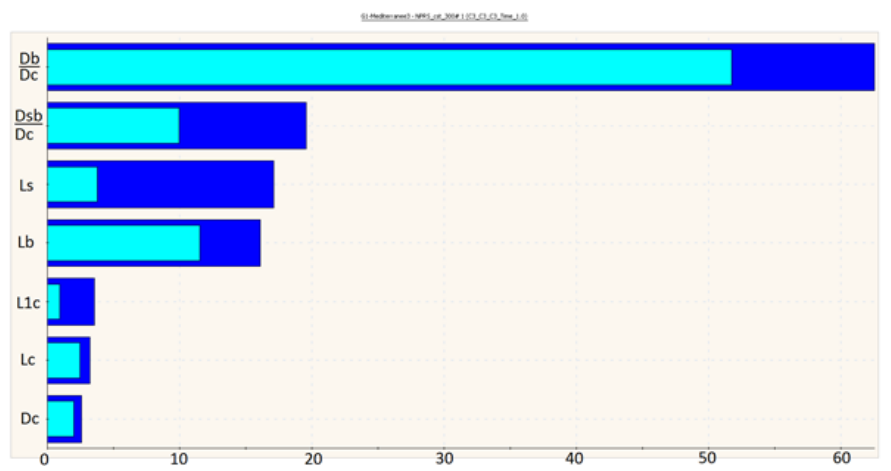

Figure 6 : First order (light blue) and total (blue) effects of the design parameters in percent on $C 3$ constraint variance.

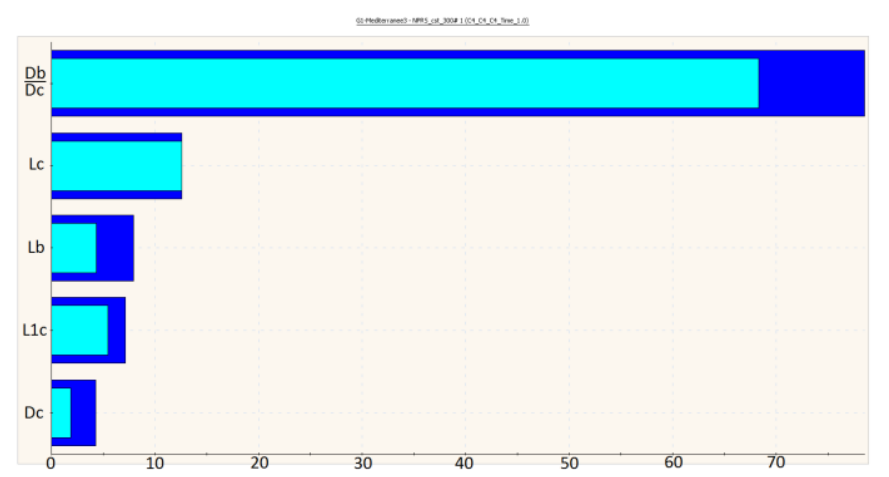

Figure 7 : First order (light blue) and total (blue) effects of the design parameters in percent, on $\mathrm{C5}$ constraint variance

Constraint $\mathrm{C} 1$ (no compression) is mainly influenced by both the buoys with $D b$, and the cable with $L c$ and $D c$, but not so much by the stiffener parameters.

For the maximum curvature constraint $\mathrm{C} 3$, the buoys are crucial as $D b$ and $L b$ are the first and second larger primary effects and the first and fourth larger total effects. The stiffener parameters $D s b$ and $L s$ are, as expected, also essential.

Finally, the constraint on the cable with respect to the sea floor (C5) is largely influenced by the diameter of the buoys $D b$. The length of the buoys $L b$ has a less significant role because it contributes less to the volume. Also, change of cable geometry with $L c$ or $L 1 c$ is prone to influence the risk of touching the sea floor.

The optimization phase can now be implemented. Because of the six nonlinear constraints, the feasible set is not convex in the parameter space, and the algorithm must faces the difficulty of local minima. To overcome this difficulty one can use a global optimization algorithm like in [8] and [9]. It is however difficult to control the stopping criteria and thus the computational time of such an algorithm. Alternately, when using an algorithm like SQA that converges to a local optimum, the choice of the initial points strongly determines the location of this solution. 
To find good diversified candidates for the initial points, a non parametric kriging response surface of each constraint is first built from the 600 points of the LHS used for the sensitivity analysis. The optimization problem defined in Eq.12 and Eq.13 is then solved fastly using these response surfaces. It is then possible to have multiple starting points (multi-start method see e.g. [28]) to have a better chance to determine the global minimum. Considering the possible error of the response surface based on the limited LHS, we select not only the best solution, but two solutions as initial points of the accurate optimization based on FEM simulations and the 28 loading cases. The selection of these two initial points also considered the constraint activation with real simulations considering the 28 loading cases. The results of the simulation-based optimization for initial points defined in Table 2 are first presented.

Table 2: Parameters value for the solution 1.

\begin{tabular}{|l|l|l|l|l|l|l|l|}
\hline & $\begin{array}{l}L_{l c} \\
(\mathrm{~m})\end{array}$ & $L_{b}(\mathrm{~m})$ & $L_{c}(\mathrm{~m})$ & $\begin{array}{l}D_{c} \\
(\mathrm{~mm})\end{array}$ & $\frac{D_{b}}{D_{c}}$ & $\begin{array}{l}L s \\
(\mathrm{~m})\end{array}$ & $\frac{D_{s b}}{D_{c}}$ \\
\hline Initial & 66.2 & 34.1 & 534.8 & 133 & 2.1 & 3.3 & 2.8 \\
\hline Optim. & 65.9 & 33.4 & 541.1 & 131 & 2.0 & 3.3 & 2.8 \\
\hline
\end{tabular}

The total cost at optimum point is composed of $45 \%$ for the armors, $20 \%$ for the buoys and 35\% for the stiffener.

The evolution of the constraints along the simulation based optimization process is illustrated on Figure 8. The maximum curvature (C3) particularly drives the optimization evolution, limiting the exploration of the parameter space with $\mathrm{C} 1$ (no compression) and C5 (risk of touching the sea floor). At the optimal solution, $\mathrm{C} 1$ and $\mathrm{C} 3$ are slightly positive, meaning that these constraints are not strictly satisfied.

The evolution of the parameters and the objective function are displayed on Figure 9. The first 15 iterations show peaks around the initial values because simulations around the initial points are performed in order to build first quadratic interpolation models of the objective function and of the constraints. Then, these quadratic models are optimized and updated with the simulations results at the current solutions. Finally, in the last iterations, we observed not converged simulations that make the SQA algorithm stop because of inaccurate quadratic models due to the lack of converged FEM simulations. They correspond to load cases with lateral current which require more static increments to guarantee the convergence. The results show that we are actually at the limit of capturing this non linearity. The amplitude of the parameter variations can be very disparate, up to two thirds of the range for the length of the cable $L c$ to less than $1 \%$ for the ratio $\frac{D b}{D c}$.

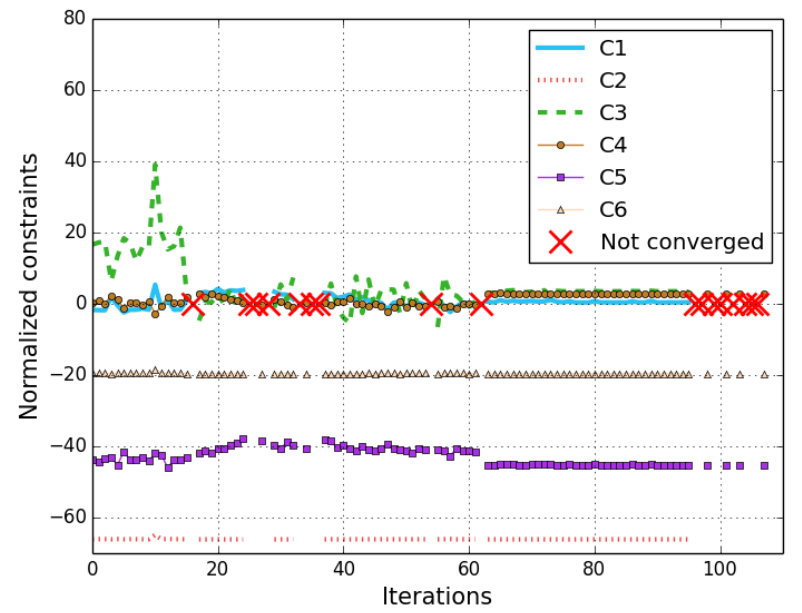

Figure 8 : evolution of the normalized constraint for solution 1.

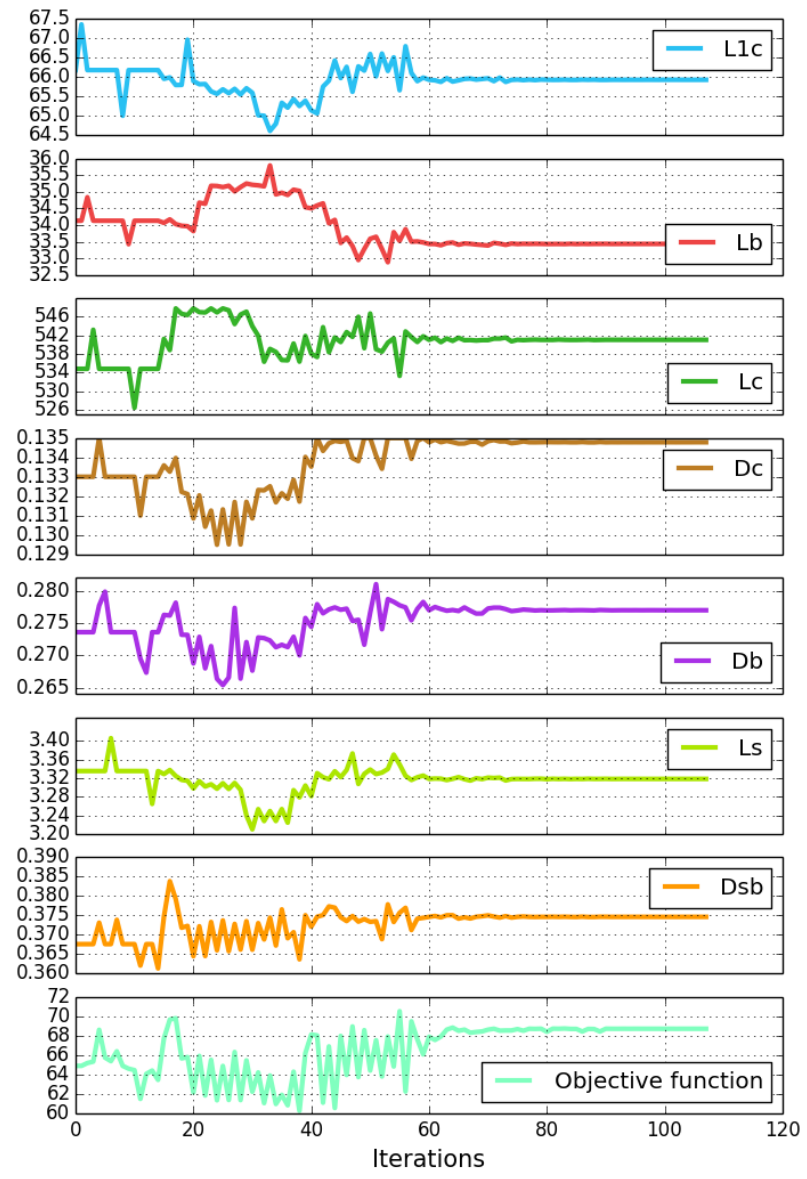

Figure 9: parameter evolution during the optimization loop for solution 1. 
Let us now present the results for the second solution.

Table 3: Parameters value for the solution 2.

\begin{tabular}{|l|l|l|l|l|c|l|l|}
\hline & $\begin{array}{l}L_{l c} \\
(\mathrm{~m})\end{array}$ & $L_{b}(\mathrm{~m})$ & $L_{c}(\mathrm{~m})$ & $\begin{array}{l}D_{c} \\
(\mathrm{~mm})\end{array}$ & $\frac{D_{b}}{D_{c}}$ & $\begin{array}{l}L s \\
(\mathrm{~m})\end{array}$ & $\frac{D_{s b}}{D_{c}}$ \\
\hline Initial & 65.5 & 34.5 & 535.0 & 131.0 & 2.0 & 3.4 & 3.0 \\
\hline Optim. & 64.1 & 33.4 & 535.0 & 131.0 & 2.0 & 3.3 & 3.0 \\
\hline
\end{tabular}

The total cost at optimum point is composed of $38 \%$ for the armors, $20 \%$ for the buoys and $42 \%$ for the stiffener.

The evolution of the constraints is illustrated on Figure 10 and again the optimization is driven by $\mathrm{C} 3, \mathrm{C} 1$ and $\mathrm{C} 5$. However this optimal solution strictly satisfies all the constraints.

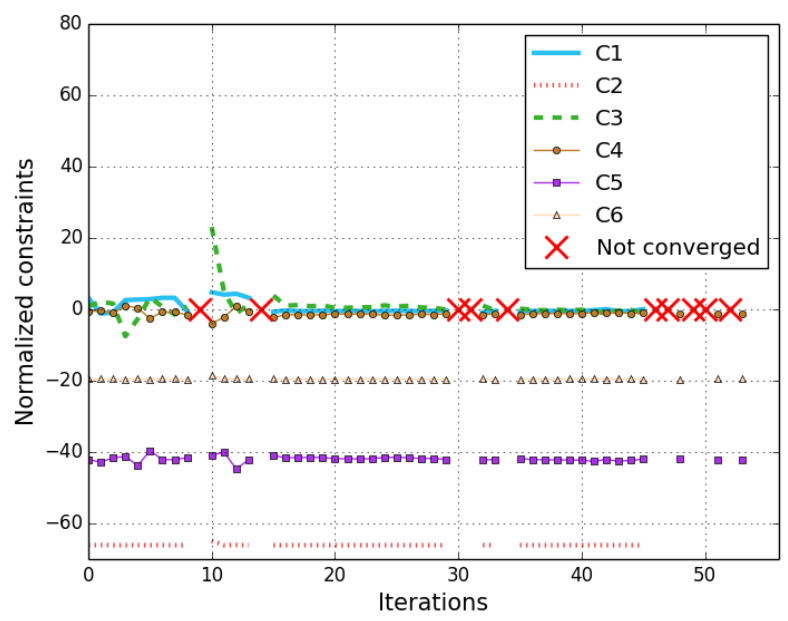

Figure 10 : evolution of the normalized constraint for solution 2.

The evolution of the parameters and the objective function are displayed on Figure 11. The initial parameters were already close to their final values with the notable exception of $L 1 c$ which was reduced because of active constraints.
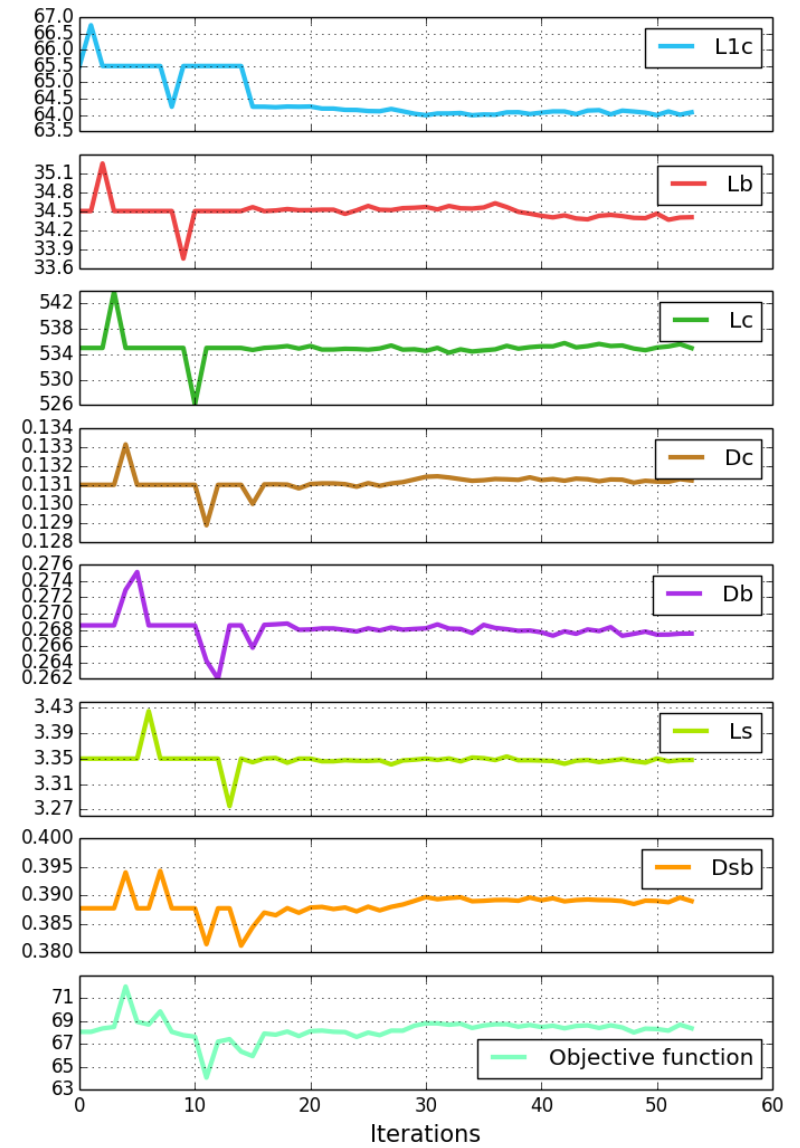

Figure 11: parameter evolution during the optimization loop for solution 2.

\section{CONCLUSION}

This paper presents a new methodology for the design optimization of offshore wind farm inter array cable exploiting FEM hydrodynamic simulations based on the derivative free SQA optimization algorithm developed by IFPEN. This methodology is an efficient way to avoid limitations of Finite Difference gradient computations when the user has no access to the sources of the aero-hydrodynamic simulation solver.

To illustrate the potential of this approach, a case study is considered with a lazy wave cable configuration for 28 ULS extreme load cases. We compute solutions for seven parameters describing the geometry (length and diameter) of the cable, buoyancy modules and stiffener. The optimization problem which aims to minimize the material cost, is completed by six non-linear black-box constraints to ensure the cable integrity, computed from the simulation outputs. This case study could easily be extended to fatigue loads and constraints.

Analytical expressions are provided to compute the global scale mechanical properties of the cable when changing the design parameters, to set the hydrodynamic simulation inputs. 
Also, analytical expressions are given for the local stress on armor wires to compute the risk of tensile rupture.

At least because of non-convexity of the feasible set induced by the constraints, the optimization has to face the difficulty of local minima. To overcome this difficulty a multistart strategy based on a pre-optimization computed with a surrogate model is used.

The methodology involves first a computation of a kriging response surface with many fast optimizations for different initial points sampled in the design parameter space, for 6 loading cases. From these results, it is possible to select among these first solutions some candidates to initialize a more precise optimization, with all the loading cases and the FEM solver.

This response surface model is used also to perform a global sensitivity analysis to rank the parameter effects on the variance of the optimized functions. It allows for instance to detect parameters that produce weak effects on the responses and thus to check the relevance of the chosen parameterization.

Two different optimized solutions obtained from different initial points are documented. The solutions provide a similar total cost but a very different cost distribution among the cable, the buoyancy module and the stiffener individual costs.

As a perspective to this work, we consider enriching the methodology by defining more accurate criteria for the initial point selection. Another different approach could be to replace the multi-start by a first step with a global optimization technique based on adaptive surrogate response models [29], [30] and a second step with a fine local optimization with our local derivative free optimization method SQA.

\section{ACKNOWLEDGMENTS}

The authors would like to thank IFP Energies Nouvelles which has funded this work, and have benefited from the help of peoples from the Applied Mechanics Department and the Mechatronics Departments. Finally, the continuous support of Principia on Deeplines ${ }^{\mathrm{TM}}$ has been greatly appreciated.

\section{REFERENCES}

[1] Poirette Y., Perdrizet T., Gilloteaux JC., Pourtier A., and Mabile C., "A new ballasted floating support for offshore wind turbine", Proc. ASME 2014, 33rd International Conference on Ocean, Offshore and Arctic Engineering OMAE2014, San Francisco, California, USA, 2014

[2] IEA Wind Technology Collaboration Program, Annual Report, 2015

[3] Ocean Energy Systems, OES - IEA Technology Collaboration Program, Annual Report, 2015
[4] "Deep Water. The next step for offshore wind energy". European Wind Energy Association - EWEA Report, 2013.

[5] “Appel à projets - Fermes pilotes éoliennes flottantes", Agence De l'Environnement et de la Maitrise de l'Energie, ADEME, https://appelsaprojets.ademe.fr/aap/AAP_EolFlo2015-98., 2015

[6] Blanco, M.I., "The economics of wind energy" Renewable and Sustainable Energy Reviews, Vol. 13, pp. 1372-1382, 2009

[7] Clauss, GF, and Birk, L, "Hydrodynamic Shape Optimization of Large Offshore Structures," Applied Ocean Research, Vol 18 (4), pp 157-171, 1996

[8] Martins, M.A.L., Lages, E.N., Silveira ; E.S.S., "Compliant vertical access riser assessment: DOE analysis and dynamic response optimization". Applied Ocean Research, Vol. 41: pp. 28-40, 2013

[9] Yang H Z, Wang A J, Li H J., "Multi-objective optimization for deepwater dynamic umbilical installation analysis". Science China Physics, Mechanics and Astronomy, 55(8): pp 1445-1453, 2012

[10] Muskulus, M. Schafhirt, S., (2014), “Analytical gradientbased optimization of offshore wind turbine substructures under fatigue and extreme loads.", Journal of Ocean and Wind Energy, Vol. 1, No. 1, pp. 12-22, 2014

[11] Kennedy, GJ, and Martins, JRRA, "An Adjoint-based Derivative Method for Time-Dependent Aeroelastic Optimization of Flexible Aircraft", Proc. 54th AIAA/ASME/ASCE/AHS/ASC Structures, Structural Dynamics, and Materials Conference, Boston, USA, 2013

[12] Chew, K-H., Tai, K., Ng, E.Y.K., Muskulus, M., "Analytical gradient-based optimization of offshore wind turbine substructures under fatigue and extreme loads.", Marine Structures, Vol. 47, pp. 23-41, 2016

[13] Brommundt, M., Krause, L., Merz, K., Muskulus, M., "Mooring system optimization for floating wind turbines using frequency domain analysis.", Energy Procedia, Vol. 24, pp. 289-296, 2012

[14]Fylling, I., Berthelsen, P. A., "WINDOPT- An optimization tool for floating support structures for deep water wind turbines". Proc. ASME 2011, 30th International Conference on Ocean, Offshore and Arctic Engineering OMAE2011, Rotterdam, The Netherlands, pp. $1-10,2011$ 
[15] Schittkowski, K., "NLPQL: A fortran subroutine solving constrained nonlinear programming problems", Annals of Operations Research, Vol. 5(2), pp. 485-500, 1986

[16] Grady S.A., Hussaini M.Y., Abdullah M.M., "Placement of wind turbines using genetic algorithms", Renewable Energy, Vol. 30(2), pp 259-270, 2005

[17] Kusiak A, Zheng H., "Optimization of wind turbine energy and power factor with an evolutionary computation algorithm". Renewable Energy; Vol. 35(3), pp. 1324-1332, 2010

[18] Langouët, H., “Optimisation sans dérivées sous contraintes : deux applications industrielles en ingénierie de réservoir et en calibration des moteurs", $\mathrm{PhD}$ thesis, Université de Nice-Sophia Antipolis, 2011.

[19] Font, G., Sinoquet, D., Langouët, H., Castagné, M., Magand, S., "Derivative free optimization method and physical simulations coupled with statistical models for transient engine calibration". $6^{\text {th }}$ Conference Design of Experiments (DoE) in Engine Development - Innovative Development Methods for Vehicle Engines, Berlin, Germany, 2011.

[20] Langouët, H., Delbos, F., Sinoquet, D., Da Veiga, S., “A derivative free optimization method for reservoir characterization inverse problem". Proc. $12^{\text {th }}$ European Conference on the Mathematics of Oil Recovery, ECMOR XII, Oxford, UK, 2010.

[21]Conn, A. R., Scheinberg, K., and Vicente, L. N., "Introduction to Derivative-Free Optimization". Proc. Society for Industrial and Applied Mathematics (MPSSIAM Series on Optimization), Philadelphia, PA, USA, 2009

[22] Powell, M., "The NEWUOA software for unconstrained optimization without derivatives". Nonconvex Optimization and Its Applications, Vol. 83, pp. 225-297, 2006

[23] Heurtier, J.M., Biolley F., Berhault, C., Le Buhan, P. and Morin, G., "Fully coupled dynamic analysis of rigid lines and floaters behaviours in deep water ", Proc. $8^{\text {th }}$ International Offshore and Polar Engineering Conference, ISOPE1998, Montreal, Canada, 1998

[24] Berhault, C., Le Buhan, Ph., Molin, B., Bougis, J., "Diodore: a Numerical Tool for Frequency and Time Domain Analysis of the Behaviour of Moored or Towed Floating Structures". $4^{\text {th }}$ International Conference on Computer Aided Design, Manufacture and Operation in the Marine and Offshore Industries, CADMO 92, Madrid, Spain, 1992
[25]Leroy JM; Caleyron F, Poirette Y., Brusselle Dupend N., "Assessing mechanical stresses in dynamic power cables for floating offshore wind farms" Proc. ASME 2017, 36rd International Conference on Ocean, Offshore and Arctic Engineering, OMAE2017, Trondheim, Norway, submitted, 2017

[26] Det Norske Veritas, "DNV-RP-F401 - Electrical Power Cables in Subsea Applications". DNV, 2012

[27] Nasution, F., Sævik, S., Gjøsteen, J., "Fatigue analysis of copper conductor for offshore wind turbines by experimental and FE method". Energy Procedia, Vol. 24: pp 271-280, 2012

[28] Saltelli, A., Tarantola, S., Campolongo, F. and Ratto, M., "Sensitivity Analysis in Practice. A Guide to Assessing Scientific Models". Probability and Statistics Series John Wiley \& Sons Publishers, 2004

[29] György, A., Kocsis, L., "Efficient multi-start strategies for local search algorithms". Journal of Artificial Intelligence Research, 2011; Vol. 41, pp 407-444, 2011

[30] Parr J.M., "Improvement Criteria for Constraint Handling and Multiobjective Optimization", $\mathrm{PhD}$ thesis, University of Southampton, 2012

[31]Binois, M., "Uncertainty quantification on pareto fronts and high-dimensional strategies in bayesian optimization, with applications in multi-objective automotive design", $\mathrm{PhD}$ thesis, École Nationale Supérieure des Mines de Saint-Etienne, 2015 